\title{
A criança hiperactiva: diagnóstico, avaliação e intervenção
}

Ana Carolina Cordinhã, ${ }^{* *}$ José Boavida**

\section{RESUMO}

Introdução: A Perturbação de Hiperactividade e Défice de Atenção é o distúrbio neurocomportamental mais frequente, em crianças em idade escolar. As formas de apresentação desta perturbação são variáveis e os sintomas devem ser valorizados, sempre que causem prejuízo no rendimento escolar, ajuste emocional ou social da criança.

Objectivo: Efectuar uma revisão bibliográfica sobre Perturbação de Hiperactividade e Défice de Atenção, valorizando aspectos respeitantes à epidemiologia, etiopatogenia, manifestações clínicas, diagnóstico, avaliação, comorbilidades e diagnóstico diferencial, intervenção terapêutica e prognóstico.

Metodologia: Foi realizada uma pesquisa nas bases de dados Medline e Pubmed de artigos e artigos de revisão, até Dezembro de 2007. Incluíram-se nesta revisão 45 artigos. Foi também realizada pesquisa documental em obras de referência.

Conclusões: A Perturbação de Hiperactividade e Défice de Atenção é um distúrbio comportamental crónico, com capacidade para afectar significativamente ao longo da vida o desempenho académico, familiar, emocional, social e laboral. Uma avaliação cuidadosa permite o diagnóstico, que é essencialmente clínico e baseado em critérios comportamentais. Raramente têm indicação exames complementares de diagnóstico. Outras perturbações associadas, são factor de risco para uma evolução menos favorável, devendo ter-se em consideração potenciais comorbilidades. A intervenção terapêutica deve ser individualizada e a abordagem multidisciplinar, incluindo na maioria dos casos, modificações comportamentais e recurso a terapêutica com psico-estimulantes. Diversos factores influenciam a evolução, e o prognóstico nem sempre é favorável.

Pretende-se, com esta revisão bibliográfica contribuir para o esclarecimento da envolvência de uma patologia prevalente, mas muitas vezes subdiagnosticada e subvalorizada.

Palavras-Chave: Perturbação de Hiperactividade e Défice de Atenção; Diagnóstico; Intervenção não farmacológica; Metilfenidato; Prognóstico.

\section{INTRODUÇÃO}

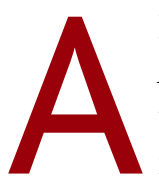

Perturbação de Hiperactividade e Défice de Atenção (PHDA) é o distúrbio neurocomportamental mais frequente em crianças em idade escolar. A maior competitividade, imposta pelos condicionalismos sociais e ambientais, implica necessidades acrescidas de desempenho escolar, independentemente das capacidades individuais. Este parece ser um dos factores responsáveis por uma maior visibilidade deste distúrbio em crianças genética e biologicamente predispostas. ${ }^{1}$

*Médica. Interna do Internato Complementar de Pediatria Médica - Hospital Pediátrico de Coimbra.

**Médico. Pediatra do Desenvolvimento, Responsável da Consulta de Hiperactividade do Centro de Desenvolvimento da Criança - Hospital Pediátrico de Coimbra.
A obrigatoriedade escolar mais prolongada, a exigência dos conteúdos curriculares e a necessidade de níveis de escolaridade mais graduados para vingar profissionalmente, numa sociedade progressivamente mais exigente, carregam consigo o despertar de crianças com menor capacidade de atenção e concentração mantidas e com necessidade de maior tempo de realização de tarefas, o que indiscutivelmente prejudicará a aprendizagem.

Faz parte da normal progressão do desenvolvimento de qualquer criança a aquisição de determinadas capacidades como a regulação das actividades, o controlo de impulsos e aumento dos tempos de concentração e atenção. Por outro lado, o diagnóstico de PHDA é clínico, baseado na evidência dos sintomas comporta- 
mentais específicos do diagnóstico; deve, por isso, ter-se em conta o contexto em que ocorrem e o grau de inconsistência em relação à idade, nível de desenvolvimento e impacto funcional. ${ }^{2}$ A PHDA é uma perturbação comportamental e não primariamente um problema disciplinar. Muitas vezes, ocorre confusão entre indisciplina ou até má educação e «hiperactividade». A dificuldade destas crianças em controlar a actividade motora, os impulsos, e em cumprir regras ou em estar quietos e não perturbarem, pode justificá-lo. ${ }^{1}$ Podem, de facto, coexistir problemas disciplinares associados à PHDA, embora nunca possam explicar a totalidade do quadro clínico. ${ }^{1}$

A PHDA é um distúrbio crónico, com capacidade para afectar significativamente o desempenho académico, familiar, emocional, social e laboral, ao longo da vida, causando sofrimento nas crianças atingidas e suas famílias. Tratando-se de uma patologia prevalente na criança em idade escolar, é solicitada de forma crescente, aos profissionais dos cuidados de saúde primários, a avaliação e intervenção nesta condição. A oportunidade e adequabilidade dessa abordagem podem condicionar definitivamente o prognóstico das crianças afectadas.

Assim sendo, é pertinente a revisão bibliográfica do tema, no sentido de alertar e esclarecer quanto à abordagem a desenvolver quando considerada a criança hiperactiva, melhorando dessa forma a qualidade dos cuidados de saúde prestados.

\section{OBJECTIVO}

Efectuar uma revisão bibliográfica sobre PHDA e proceder a uma actualização e síntese de conhecimentos, tendo em conta a informação disponível na literatura e considerando aspectos referentes a: epidemiologia, etiopatogenia, clínica, diagnóstico e avaliação, comorbilidades e diagnóstico diferencial, intervenção terapêutica (não farmacológica e farmacológica) e prognóstico.

\section{METODOLOGIA}

Foi realizada uma pesquisa nas bases de dados Medline e Pubmed de artigos e artigos de revisão, de 1998 até Dezembro de 2007, dando particular atenção aos últimos sete anos. Foram usadas as seguintes palavras-chave, como motores de busca: Hiperactividade; Crian- ça hiperactiva; Défice de atenção; PHDA; Metilfenidato; Attention-deficit; Hyperactivity disorder; Attention-deficit/hyperactivity disorder; ADHD; Attention-deficit disorder; Methylphenidate; Psychopharmacological treatment of ADHD. As referências bibliográficas dos artigos foram analisadas, para identificar bibliografia adicional. Foram seleccionados todos os artigos cujo título ou resumo foi considerado relevante, no contexto da revisão em causa. Foram posteriormente obtidos os referidos artigos, em texto integral. Incluíram-se nesta revisão 45 artigos, seleccionados com base na qualidade, abrangência dos conteúdos e na importância relativa dos autores, na área considerada. Foi também realizada pesquisa documental em obras de referência.

\section{PERTURBAÇÃO DE HIPERACTIVIDADE E DÉFICE DE ATENÇÃO \\ Epidemiologia}

Desde que foi descrita pela primeira vez em 1902 por George Still, várias designações foram evoluindo ao longo do tempo, de que são exemplo, disfunção cerebral mínima, défice de atenção, perturbação hipercinética ou síndrome psico-orgânico da criança, até à actual designação PHDA, de acordo com a classificação da Academia Americana de Psiquiatria. ${ }^{3}$ Pode definir-se como sendo um distúrbio persistente do desenvolvimento psicológico, caracterizado por elevados níveis de desatenção e/ou hiperactividade e comportamentos impulsivos, com intensidade mais grave e frequente que o habitualmente observado, nos indivíduos com um nível de desenvolvimento semelhante, e com evidência de interferência social, académica ou laboral.

As formas de apresentação e o impacto desta perturbação são individualmente variáveis, existindo uma heterogeneidade não apenas fenotípica, mas também genética, fisiopatológica e neuropsicológica; ${ }^{4}$ assim, o seu impacto pode ser apenas ligeiro e transitório, ou ter grave interferência na vida da criança. Deve ter-se presente, no entanto, que os sintomas são valorizáveis, sempre que causem prejuízo no rendimento escolar, ajuste emocional e/ou social.

É a perturbação do desenvolvimento da infância e adolescência mais estudado e o distúrbio neurocomportamental mais frequente na criança de idade escolar, com uma prevalência estimada de cerca de $7 \%$, variando de 4 a 19\%. ${ }^{2,4}$ Além disso, outros 5-10\% apre- 
sentam sintomas de PHDA insuficientes para estabelecer o diagnóstico, mas que continuam a perturbar a evolução normal da aprendizagem e o sucesso educativo. É mais frequentemente diagnosticada em idade escolar, em função das maiores exigências sociais e académicas; no entanto, também pode manifestar-se em idades mais precoces, nomeadamente em pré-escolares.

A PHDA é três a quatro vezes mais comum no sexo masculino $^{2,5,7}$ (ratio variável de 2,5-9:1, consoante a população em estudo), ${ }^{2}$ embora na adolescência a diferença entre sexos seja menos evidente. No sexo feminino, a probabilidade de estarem presentes critérios de PHDA do subtipo desatento é 2,2 vezes superior, e os sintomas de hiperactividade e impulsividade, apesar de presentes, são geralmente de menor intensidade., ${ }^{8,9}$ Por esse motivo, presume-se que o número de casos de PHDA subdiagnosticados em raparigas seja significativo.

Em 60 a 85\% das crianças com PHDA, o diagnóstico persiste durante a adolescência, ou seja, na maioria dos casos, não cura com o início da puberdade. ${ }^{4,10,11}$ Quando o diagnóstico é feito na infância, o acompanhamento e tratamento devem ser continuados enquanto necessários; no entanto, alguns adolescentes apresentam-se sem nunca terem sido diagnosticados, e os sintomas do distúrbio podem permanecer subtis neste grupo etário. ${ }^{11}$

\section{Etiopatogenia}

A etiopatogenia exacta é desconhecida e provavelmente complexa e multifactorial. ${ }^{4,7,10,12-16}$ Os vários estudos disponíveis indicam que a principal causa é genética, ${ }^{10,15}$ com uma hereditabilidade estimada em 65 a $90 \%{ }^{4,7,17}$ (gémeos monozigóticos). Sabe-se que existe uma predisposição ou agregação familiar: o risco em irmãos de crianças com PHDA é três a cinco vezes superior ao da população geral e os pais terão duas a oito vezes maior probabilidade de apresentarem os critérios de diagnóstico ${ }^{7,14}$ Estudos de Genética Molecular revelaram defeitos em genes dos receptores 2, 4 e 5 da dopamina, do transportador de dopamina e da dopamina $\beta$-hidroxilase, do gene do transportador da serotonina, do receptor $1 \mathrm{~B}$ da serotonina e da proteína sinaptossomal associada ao gene 25 (SNAP-25).$^{4,15-18} \mathrm{~A}$ diminuição de neurotransmissores como a dopamina, noradrenalina e serotonina, condicionada por factores genéticos, causa uma desregulação catecolaminérgica central, que pode também contribuir para a fisiopatologia do distúrbio. ${ }^{4,13}$ Esta hipótese é apoiada pela eficácia terapêutica das substâncias com actividade dopaminérgica e serotoninérgica.

As crianças com PHDA têm défices em funções executivas, ou seja, nos processos neurocognitivos que permitem a capacidade de resolução de problemas, para atingir um determinado objectivo, ${ }^{10}$ o que é confirmado por estudos neuropsicológicos. Diversas funções cognitivas superiores podem revelar alterações. Podem referir-se os processos de motivação, o défice entre o processamento da informação recebida e a resposta produzida, ou a incapacidade de inibir a resposta adequadamente, até que seja processada toda a informação; também podem estar afectadas, a capacidade de vigília e de planeamento de tarefas, assim como a memória de trabalho. ${ }^{4,10}$

Em diversas estruturas cerebrais são demonstráveis diferenças discretas na estrutura, volume e função; é o caso do córtex do lobo frontal, temporal e parietal, gânglios basais (striatum), áreas do corpo caloso e cerebelo (vérmis). ${ }^{4,12}$ Quando surge necessidade de desempenhar tarefas que requerem controlo inibitório, parece haver diferenças na activação do lobo frontal, núcleo caudado e cíngula anterior. Essas anomalias, demonstráveis por RMN cerebral (estrutural, volumétrica e funcional), electrofisiologia e estimulação magnética transcraneana, são precoces, não progressivas e independentes do tratamento com estimulantes. ${ }^{4}$ Estudos de imagem funcional (Positron Emission Tomography - PET e Single Photon Emission CT - SPECT), sugerem alteração da actividade da dopamina-descarboxilase nas áreas pré-frontais e striatum, e também aumento da capacidade de ligação do transportador de dopamina, reduzindo assim a actividade nas vias fronto-estriadas. ${ }^{4,13}$

A interacção gene-ambiente é provável e factores não genéticos são determinantes para o fenótipo. Apesar de resultados nem sempre com significância estatística, diversos estudos indicam que a exposição pré-natal a álcool e drogas, como a nicotina e benzodiazepinas, assim como complicações pré e peri-natais (baixo peso de nascimento, prematuridade, traumatismo cranio-encefálico e anóxia), podem contribuir para problemas comportamentais futuros..$^{14,19-25}$ Entre outros factores ambientais podem também referir-se factores 


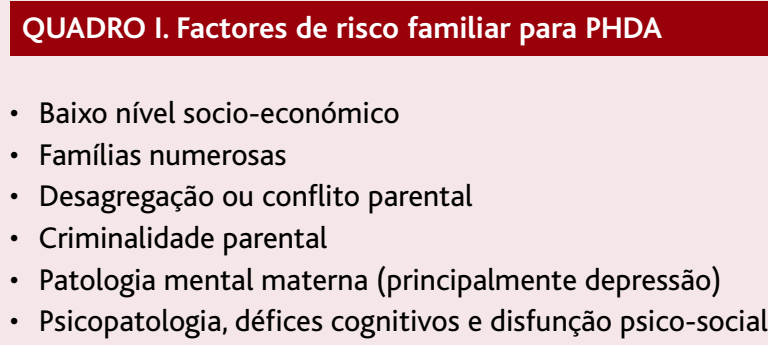

- Baixo nível socio-económico

- Famílias numerosas

- Desagregação ou conflito parental

- Criminalidade parental

- Patologia mental materna (principalmente depressão)

- Psicopatologia, défices cognitivos e disfunção psico-social

Abreviaturas: PHDA: Perturbação de hiperactividade e défice de atenção

alimentares (açúcares, corantes e conservantes, embora os resultados dos estudos sejam controversos), a institucionalização, ou privação afectiva precoce e grave e a exposição a níveis tóxicos de chumbo. ${ }^{14}$

Embora não se considere existir relação directa entre a vida familiar e PHDA, podem de facto considerar-se diversos factores de risco (Quadro I). ${ }^{26}$ Deve ter-se presente, no entanto, que tanto pais como educadores devem preocupar-se menos com a causa, e mais com medidas que reduzam o impacto deste distúrbio na vida das crianças. A qualidade das relações com a família e a escola pode atenuar ou agravar o distúrbio. ${ }^{4}$

\section{MANIFESTAÇÕES CLÍNICAS}

A desatenção, a hiperactividade e a impulsividade são os sintomas nucleares da PHDA, e manifestam-se com uma intensidade mais grave e frequente que o habitualmente observado nos indivíduos com um nível semelhante de desenvolvimento. Apesar de nem sempre ser óbvia, a desatenção é um sintoma constante. ${ }^{6}$ Estas crianças distraem-se facilmente, não tendo capacidade de manter a atenção até concluirem uma tarefa. Cometem erros facilmente por descuido, não dão atenção a pormenores e têm dificuldade em seleccionar a informação. Têm dificuldade em estar atentos a dois estímulos simultâneos, e em seguir instruções; evitam tarefas que exigem concentração mantida, como os trabalhos escolares, mas, mesmo em jogos ou actividades de lazer, interrompem frequentemente e não os completam. Esquecem-se das actividades habituais, perdem brinquedos ou material escolar e mostram-se desorganizados. Quando se lhes dirigem directamente, podem parecer não escutar.

O componente de hiperactividade torna-se mais notório em situações que requerem maior tranquilidade, manifestando-se como actividade quase permanente e descontrolada. Revelam dificuldades em dedicarem-se a actividades de forma calma, ou até em manterem-se sentados, levantando-se frequentemente ou correndo e saltando excessivamente, em situações em que é desadequado fazê-lo. Por outro lado, a impulsividade conduz as crianças a actuarem antes de pensar, sem prever as consequências dessas acções. Este tipo de comportamento pode ser causador de acidentes, por não serem ponderadas as consequências de actividades potencialmente perigosas. Falam demasiado e respondem a perguntas que não foram completadas; têm dificuldade em aguardar pela vez e interrompem facilmente os colegas.

A conjugação destes comportamentos torna estas crianças «explosivas». ${ }^{6}$ São ainda frequentes, as dificuldades do sono, com uma prevalência que pode atingir os $50 \%$; uma vez que, também podem surgir como efeito secundário da medicação para PHDA, é essencial estabelecer um padrão do sono, na avaliação inicial destas crianças. ${ }^{27}$ Em situações pouco apelativas, sem o estímulo da novidade, ou que requerem atenção mantida por maiores períodos de tempo, os sintomas podem piorar. Por outro lado, se a situação for estimulante ou se há perspectivas de recompensa se o comportamento for adequado, ou ainda numa situação face a face, como é o caso de uma consulta médica, os sintomas podem ser mínimos. Isto pode estar na origem de uma falsa percepção de que os sintomas dependem da vontade da criança, conduzindo a culpabilização pelos pais e professores, e rejeição pelos pares.

Na maioria das crianças com PHDA, a distracção fácil pelas dificuldades na atenção selectiva, as dificuldades no controlo de impulsos e em seguir instruções, condicionam lentidão na realização de tarefas e execução de funções, ineficácia, baixa tolerância à frustração e baixa auto-estima. O mau aproveitamento escolar e a desadaptação social inerentes a este distúrbio causam sofrimento na criança e eventuais consequências no adolescente (maior risco de criminalidade, comportamentos anti-sociais, acidentes de viação e adicção de substâncias) e no adulto (baixa auto-estima, dificuldades sociais e laborais).

\section{DIAGNÓSTICO}

Os sintomas são inespecíficos, daí que o diagnóstico 
possa tornar-se problemático. Por outro lado, não há achados do exame objectivo ou exames complementares de diagnóstico que permitam confirmar ou excluir o diagnóstico. Trata-se, portanto, de um diagnóstico clínico, baseado em critérios comportamentais que estão sujeitos a subjectividade na avaliação. Apesar das anomalias estruturais e funcionais, os estudos de imagem não servem como método de diagnóstico, e não está indicado nenhum exame complementar, laboratorial ou imagiológico.

De acordo com as recomendações mais recentes, são utilizados para diagnóstico os critérios comportamentais definidos no Manual de Diagnóstico e Estatística das Perturbações Mentais, da Academia Americana de Psiquiatria (DSM IV) (Quadro II)., ${ }^{2,3}$ Para que se possa estabelecer o diagnóstico, a criança deve cumprir pelo menos seis critérios de uma das categorias, e todos os critérios adicionais:

1. Quantidade: presentes pelo menos 6 dos 9 da categoria I (PHDA tipo desatento) ou categoria II (PHDA tipo hiperactivo/impulsivo) ou ambos (PHDA tipo combinado).

2. Duração: presentes por um período mínimo de 6 meses com uma intensidade inconsistente com o nível de desenvolvimento do indivíduo e de forma mal adaptativa.

3. Início: sintomas presentes, por definição antes dos 7 anos (idade escolar) e frequentemente antes dos 5 anos. $^{4}$

4. Contexto: presente em duas ou mais situações (dois ambientes ou contextos diferentes, por exemplo casa e escola ou trabalho).

5. Provas: evidências claras de disfunção clinicamente significativa do funcionamento social, académico ou ocupacional. O diagnóstico implica não só uma frequência e severidade superior dos sintomas, mas também interferência com o funcionamento nos principais contextos da vida da criança (em casa, na escola, com os amigos ou outro) ${ }^{4,5}$ Crianças com sintomas comportamentais de PHDA, mas que não demonstram prejuízo funcional, não reúnem critérios diagnósticos de PHDA. ${ }^{4,5}$

6. Exclusão: os sintomas não ocorrem exclusivamente durante uma perturbação global do desenvolvimento, esquizofrenia, ou outras psicoses e não são melhor explicados por outra perturbação mental (per-

\section{QUADRO II. Critérios DSM IV para diagnóstico de PHDA}

\section{Sintomas de desatenção}

- Não dá atenção aos pormenores ou comete erros por desatenção, nas tarefas escolares, trabalho ou actividades lúdicas

- Dificuldade em manter a atenção em actividades ou tarefas

- Parece não ouvir quando se lhe dirigem directamente

- Não segue instruções e não termina tarefas (não devido a comportamento de oposição ou por não compreender as instruções)

- Dificuldade em organizar tarefas e actividades

- Não gosta ou evita iniciar tarefas que requerem concentração

- Perde facilmente material necessário a tarefas ou actividades que terá de realizar (material escolar, livros, brinquedos).

- Distrai-se facilmente com estímulos extrínsecos irrelevantes

- Esquece-se com facilidade das tarefas diárias

II. Sintomas de Hiperactividade e Impulsividade

- Hiperactividade

- Mexe excessivamente mãos e pés ou permanece irrequieto na cadeira, quando sentado

- Não se mantém sentado quando deve

- Corre e trepa excessivamente em situações em que é inapropriado fazê-lo

- Dificuldade em dedicar-se a actividades de forma calma

- Sempre pronto a mudar, age como se estivesse «ligado à electricidade»

- Fala demasiado (verborreia)

- Impulsividade

- Precipita respostas antes que as perguntas tenham sido completadas

- Dificuldade em esperar pela sua vez

- Interrompe ou perturba os outros, interferindo nas suas actividades

Abreviaturas: DSM IV: Manual de diagnóstico e estatística das perturbações mentais, da Academia Americana de Psiquiatria; PHDA: Perturbação de hiperactividade e défice de atenção

turbações do humor, distúrbio de ansiedade, distúrbio dissociativo ou distúrbio de personalidade).

Podem considerar-se três tipos de PHDA, em função do predomínio de sintomas de desatenção e hiperactividade-impulsividade: combinado ou misto, em que 


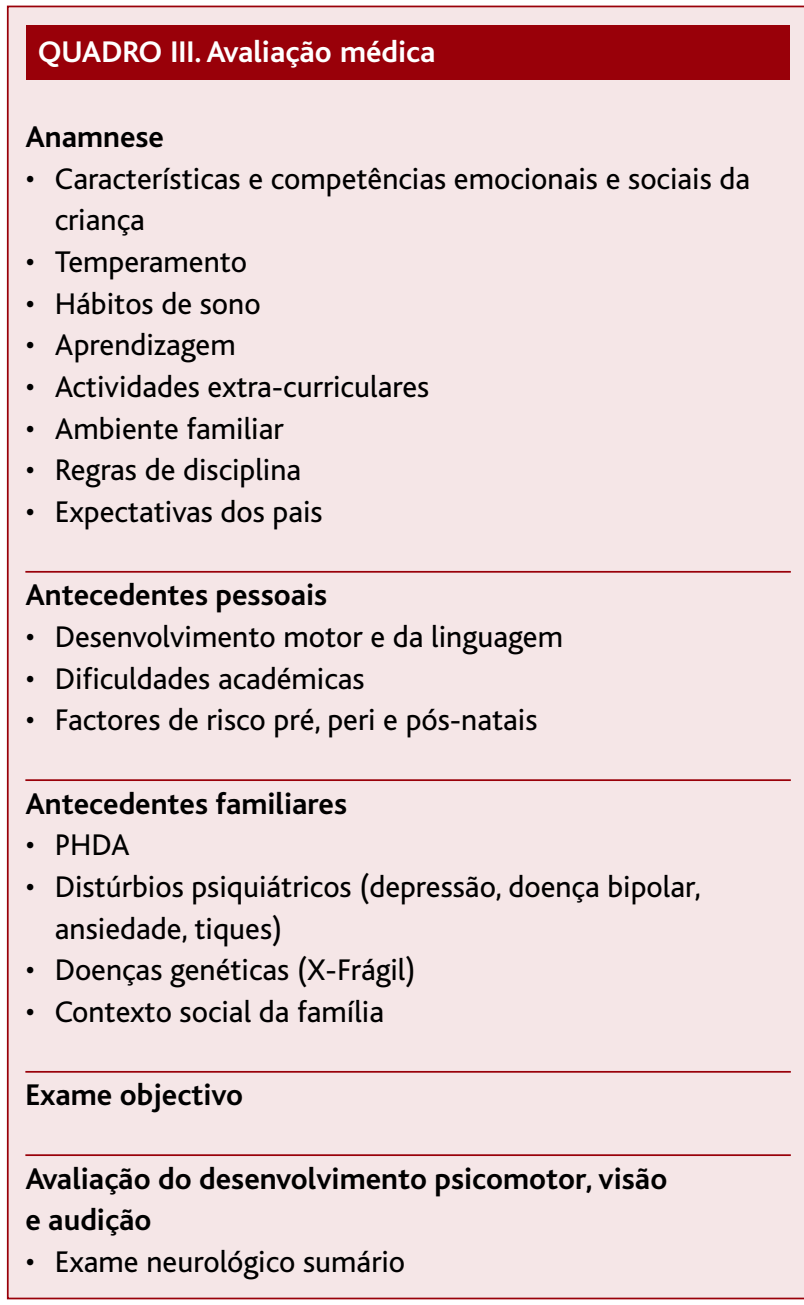

Abreviaturas: PHDA: Perturbação de hiperactividade e défice de atenção

coexistem os dois tipos de sintomas, preenchendo pelo menos seis dos nove comportamentos de ambas as categorias; predominantemante desatento, quando preenchem pelo menos seis dos nove comportamentos de desatenção e predominantemente hiperactivo e impulsivo, quando preenchem pelo menos seis dos nove comportamentos de hiperactividade-impulsividade. ${ }^{2}$

\section{AVALIAÇÃO}

A criança com suspeita diagnóstica de PHDA requer uma avaliação cuidadosa, de preferência por uma equipa multidisciplinar. Deve ter-se em conta que estas crianças podem apresentar motivos de consulta diversos, como comportamento hiperactivo ou perturbador

\section{QUADRO IV. Avaliação comportamental}

- Observação directa na consulta

- Informação de pais e professores

- Critérios DSM-IV

- Questionários:

- Conner (pais/professores)

- Achenbach (pais/professores/auto)

- Comportamentos co-mórbidos (agressividade, conduta, oposição)

Abreviaturas: DSM-IV: Manual de diagnóstico e estatística das perturbações mentais, da Academia Americana de Psiquiatria

na sala de aula, dificuldades de aprendizagem, desatenção, baixa auto-estima e perturbações no relacionamento com os pais, professores ou pares.

A sua avaliação deve incluir uma abordagem médica (história clínica e exame objectivo) e comportamental (dirigida aos três componentes da PHDA: atenção, actividade e impulsos), (Quadros III e IV) ${ }^{2,4,10}$ Deve fazer-se um questionário cuidadoso aos pais, sobre os comportamentos incluídos nos critérios de diagnóstico DSM-IV e se presentes, determinar para cada um a sua duração, frequência e gravidade. É necessário questionar acerca da idade de início dos sintomas, o contexto em que ocorrem e o seu impacto funcional, particularmente em termos de aprendizagem.

Pode também considerar-se uma avaliação cognitiva e académica, apesar de não serem essenciais para estabelecer o diagnóstico. Devem destinar-se essencialmente a casos em que existam dificuldades específicas de aprendizagem ou suspeita de défice cognitivo. ${ }^{10}$ Esta avaliação permite estabelecer um perfil psicométrico (pelo psicólogo) e de desempenho académico (pelo professor). Assim, pode caracterizar-se a criança quanto a capacidades atencionais, de aprendizagem e inteligência, permitindo depois individualizar o plano de intervenção. $^{4}$

Ressalta-se a importância de determinar a presença não só de critérios de diagnóstico, mas também de sinais ou sintomas de outros distúrbios associados, uma vez que essas perturbações são factor de risco para uma evolução menos favorável. ${ }^{4}$ Nesse sentido, deve questionar-se na história clínica sobre baixa auto-estima, humor depressivo, agressividade e comportamentos de oposição. 
A observação directa pode não ser esclarecedora sobre o comportamento habitual da criança, fora do ambiente da consulta. Como instrumento auxiliar de diagnóstico pode recorrer-se a escalas padronizadas de comportamentos, que permitem a análise e quantificação de características, estabelecendo valores normativos, tendo em consideração o sexo e idade da criança. ${ }^{5,10}$ É o caso dos questionários de Conners e Achenbach, ${ }^{5,28,29}$ preenchidos pelos pais e professores, que informam sobre o comportamento da criança, nomeadamente em termos de atenção, hiperactividade, competências sociais e comportamentos de oposição. Têm uma sensibilidade e especificidade superiores a $94 \%,{ }^{5}$ mas devem ser sempre interpretados no contexto de uma avaliação global da criança. A discrepância nos resultados obtidos nos questionários dos pais e professores, em ambos os sentidos, não exclui o diagnóstico, devendo obter-se informações adicionais (professores anteriores, treinadores ou monitores em actividades extra-escolares, catequistas, ou outros). Essa disparidade pode dever-se a diferentes expectativas, níveis de estruturação, estratégias comportamentais e circuns-

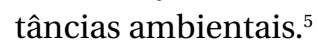

\section{COMORBILIDADES E DIAGNÓSTICO DIFERENCIAL}

Diversas condições médicas, psicológicas ou de desenvolvimento, podem coexistir, partilhar sintomas ou sobrepôr-se à PHDA,,$^{5,6,10}$ identificando-se menos frequentemente como diagnóstico isolado. ${ }^{30,31}$ Estima-se que $1 / 3$ destas crianças tenha uma ou mais comorbilidades associadas. ${ }^{5} \mathrm{O}$ facto de os sintomas desta perturbação serem inespecíficos dificulta o diagnóstico diferencial e, apesar de nem sempre ser possível o diagnóstico preciso, a presença de comorbilidades deve ser considerada na avaliação destas crianças, uma vez que agrava o prognóstico da PHDA. Da mesma forma, perante o diagnóstico de uma destas perturbações deve pesquisar-se PHDA, como distúrbio coexistente. ${ }^{5,31}$ Podem referir-se, as seguintes: ${ }^{5,10,31}$

Outras perturbações do comportamento, como o distúrbio de oposição (em 54 a 84\% dos casos vs população geral 2 a 16\%) e o distúrbio da conduta (em 14 a 26\%); nestas situações há tendência para um comportamento negativista, anti-social e hostil. ${ }^{6}$ Frequentemente devem ser encarados não como diagnóstico diferencial ou comorbilidade, mas sim como complica- ção, dado que estudos longitudinais apontam a hiperactividade em idade escolar como factor de risco independente para distúrbio da conduta no futuro. ${ }^{4}$

Perturbação de ansiedade em $34 \%$ (até $1 / 3$ dos casos vs população geral 5\%) e perturbações do humor (depressão, distimia, distúrbio bipolar) em $4 \%$; a baixa auto-estima e insegurança, inerentes ao insucesso escolar e das interacções sociais podem justificar estas associações. ${ }^{4}$

Dificuldades escolares, na maioria das crianças determinadas não só pela perturbação propriamente dita, mas também pela ocorrência simultânea de dificuldades específicas de aprendizagem (como dislexia e discalculia) e perturbações da linguagem, mais prevalentes do que na população geral ( 25 a $35 \%$ vs 10 a 16\%).

Por outro lado, perturbações cognitivas e do processamento, como défice cognitivo ou atraso mental e distúrbios neurológicos (epilepsia e efeitos secundários de medicação anti-epiléptica, infecções do sistema nervoso central, doenças degenerativas, síndrome fetal alcoólico), podem ser uma causa possível de comportamento hiperactivo. ${ }^{4}$

São descritos tiques em $11 \%$ das crianças com PHDA, desenvolvendo-se geralmente em idade escolar precoce, estando o seu impacto psicossocial mais condicionado pela PHDA. ${ }^{4}$

A perturbação do desenvolvimento da coordenação motora associa-se frequentemente com a PHDA, daí a designação DAMP - Deficits in attention, motor control and perception, para os casos em que ambas as situações coexistem: são crianças «desajeitadas», pouco habilidosas em actividades que impliquem coordenação motora sensorial, como a escrita ou alguns desportos; o tratamento justifica-se quando há interferência significativa nos objectivos académicos, ou nas actividades de vida diária. ${ }^{4}$

Défices sensoriais, como o défice auditivo, podem ser a causa da desatenção da criança por dificuldades em compreender, ou ouvir o que está a ser dito na sala de aulas.

Devem ainda considerar-se distúrbios ambientais, como psicopatologia familiar ou colocação escolar desadequada, assim como doenças endócrinas (hipertiroidismo) e metabólicas.

\section{INTERVENÇÃO TERAPÊUTICA}

A intervenção precoce e atempada é desejável, consi- 
derando as consequências da PHDA. O plano terapêutico deve ter sempre em conta a necessidade de reconhecer a PHDA como situação crónica e com potencial de persistir na vida adulta; na maioria dos casos inclui farmacoterapia, associada ou não a terapia comportamental. ${ }^{10,32,33}$ Há necessidade de aceitar e compreender o distúrbio, criando uma aliança terapêutica entre a criança, os pais, o médico e o professor; essa atitude visa, sobretudo, o esclarecimento e aconselhamento adequado de todos os intervenientes, que possibilite implementar mudanças de atitudes e adaptação a diversas situações, além de reforçar positivamente os comportamentos adequados.

O objectivo do tratamento é o controlo dos sintomas de desatenção, hiperactividade e impulsividade, melhorando o desempenho académico e as competências sociais, permitindo dessa forma aumentar a auto- estima da criança. Podem considerar-se estratégias terapêuticas comportamentais e educacionais, apoio educativo individualizado ou, eventualmente, apoio educativo especial, actividades extra-académicas, terapia familiar e participação em grupos de pais ou de apoio da comunidade. ${ }^{2,4,6,10,34}$ Deve incluir-se uma prova terapêutica com um psico-estimulante, desde que não estejam contra-indicados, em associação a outras intervenções, individualizadas em função da heterogeneidade deste grupo de crianças.

\section{TERAPÊUTICA NÃO FARMACOLÓGICA}

A terapêutica comportamental diz respeito a modificações que devem ter lugar em casa, na escola e em qualquer outro local ou contexto em que a criança passe algum tempo do seu dia. A etapa fundamental é obter a compreensão e aceitação do problema, tendo sempre presente que não se trata de um problema disciplinar, ou dependente da vontade da criança. É favorável a adaptação de expectativas e exigências, assim como a modificação de atitudes dos pais e professores/educadores, evitando a crítica frequente e situações que conduzam previsivelmente ao insucesso. Deve sempre ser promovido o reforço positivo, valorizando comportamentos adequados. Podem referir-se várias estratégias educacionais, a ter em conta na intervenção na escola (Quadro V). 4,6,34,35

As actividades extra-académicas assumem também um papel determinante: ajudam a libertar tensões acu-
QUADRO V. Estratégias educacionais em crianças com PHDA

- Ambiente tranquilo, com turma reduzida

- Apoio educativo individualizado ou eventual apoio da educação especial

- Evitar fontes de distracção, localização preferencial na primeira fila, próximo do professor

- Estabelecer regras de funcionamento na sala de aulas, regularmente recordadas

- Estabelecer planos diários de actividades, adaptados às características atencionais e comportamentais da criança

- Associar tarefas que impliquem alguma actividade motora

- Sempre que possível usar estímulos visuais

- As instruções devem ser curtas e frequentemente repetidas, avaliando a sua compreensão

- Apoio na organização do pensamento

- Evitar confrontação ou crítica frequente

- Reforço positivo, com reconhecimento público e elogio das aquisições

- Incentivo à participação frequente do aluno nas tarefas escolares

- Evitar a exposição da criança a situações em que terá dificuldade em controlar-se (por exemplo, filas de espera)

- Os trabalhos de casa devem ter um plano organizado, e sempre que possível, apoio dos pais

Abreviaturas: PHDA: Perturbação de hiperactividade e défice de atenção

muladas, contribuem para a aquisição de competências sociais e promovem o cumprimento de regras, além de melhorar a condição física da criança. Qualquer forma de ocupação de tempos livres é potencialmente benéfica, concretamente a prática de um desporto. Pode recomendar-se a natação, o futebol, o ciclismo, o escutismo ou as artes marciais. ${ }^{6,36}$ Deve no entanto ter-se presente que não há boas e más modalidades desportivas, qualquer uma é adequada, desde que seja do agrado da criança e esteja disponível e acessível no seu contexto socio-familiar. ${ }^{6}$

\section{TERAPÊUTICA FARMACOLÓGICA}

Está comprovada uma eficácia superior dos tratamentos que incluíram psicofármacos, em relação ao uso de terapia comportamental isolada. . $, 4-6,10,32,33$ Os psico-estimulantes são fármacos de primeira linha na terapêutica farmacológica da PHDA. São usados desde os anos 


\begin{tabular}{|lccc}
\hline \multicolumn{2}{|l}{ QUADRO VI. formulações terapêuticas de metilfenidato disponíveis em portugal } \\
& Acção curta & Acção intermédia & Acção longa \\
\hline Nome comercial & Rubifen ${ }^{\circledR}$ & Ritalina LA $^{\circledR}$ & Concerta $^{\circledR}$ \\
\hline Dosagem & $10 \mathrm{mg}$ & $20,30,40 \mathrm{mg}$ & $18,36 \mathrm{mg}$ \\
\hline Dose inicial & $5-10 \mathrm{mg}$ & $20 \mathrm{mg}$ & $18 \mathrm{mg}$ \\
\hline Dose máxima & $60 \mathrm{mg}$ & $60 \mathrm{mg}$ & $72 \mathrm{mg}$ \\
\hline Início de acção & $20-60 \mathrm{~min}$ & $30 \mathrm{~min}-2 \mathrm{~h}$ & $30 \mathrm{~min}-2 \mathrm{~h}$ \\
\hline Duração de acção & 3 a 6 horas & 6 a 8 horas & 10 a 12 horas
\end{tabular}

30 e têm uma extensa investigação disponível sobre segurança e eficácia, com taxas de resposta de 70 a $80 \%{ }^{2,10,12,27}$ Os efeitos sobre a hiperactividade, impulsividade e desatenção estão claramente demonstrados, sendo variáveis e questionáveis sobre a cognição, aprendizagem e comportamentos de agressividade. ${ }^{6}$ Trata-se de fármacos simpaticomiméticos, que corrigem alterações bioquímicas, influenciando a atenção e o controlo de impulsos. A medicação não deve ser usada de forma isolada, em qualquer caso; requer sempre associação de modificações comportamentais. ${ }^{6}$

O Metilfenidato é o único psico-estimulante disponível em Portugal. Estes fármacos geralmente são usados apenas em crianças com idade igual ou superior a 6 anos. Estão em curso estudos sobre a aplicação terapêutica do Metilfenidato, em idade pré-escolar; os resultados preliminares apontam para que, nesse grupo etário, a dose média eficaz seja inferior e para a maior incidência de efeitos adversos, nomeadamente emocionais. ${ }^{10,37-39}$ Não são responsáveis por qualquer tipo de habituação, dependência ou tolerância. Pelo contrário, o tratamento a longo prazo com psico-estimulantes pode ser um factor de protecção, no que respeita a distúrbios psiquiátricos e abuso de substâncias na adolescência e idade adulta. ${ }^{10,11,40-44}$ Este fármaco é seguro e bem tolerado. No que respeita a efeitos secundários, apesar de pouco frequentes e transitórios, raramente justificando a interrupção do tratamento, pode haver referência aos seguintes: ${ }^{2,4,6,10,11}$ anorexia, epigastralgias, perda ponderal, náuseas, obstipação, insónia, ansiedade e tremor, depressão ou labilidade emocional, tiques e maneirismos, cefaleias e tonturas. Ligeiras alterações na dieta e/ ou no horário da medicação podem atenuá-los.

Um estudo recente não demonstrou efeitos clinicamente relevantes, a longo prazo, na tensão arterial, fre- quência cardíaca, função hepática e hematológica. ${ }^{7}$ Os efeitos da terapêutica sobre o crescimento têm suscitado preocupação, e os resultados da literatura disponível são controversos. Os estudos mais recentes sugerem uma redução na velocidade de crescimento esperada, nos primeiros anos de tratamento. Essa desaceleração, no entanto, não se traduz em estaturas abaixo da média para a idade, assim como não parece haver diferenças clinicamente significativas em relação aos controlos, na idade adulta. ${ }^{45-47}$ Também recentemente, outro estudo, em que todas as crianças interromperam o tratamento durante as férias escolares, o que pode ter influenciado o resultado, não revelou efeito significativo na velocidade de crescimento. ${ }^{10}$

O Metilfenidato tem uma eficácia documentada de $80 \%$ dos casos em tratamento na Consulta de Desenvolvimento do Hospital Pediátrico de Coimbra. ${ }^{44} \mathrm{~A}$ dose inicial recomendada é geralmente $0,3 \mathrm{mg} / \mathrm{kg} / \mathrm{dia}$, até uma dose diária máxima de $1 \mathrm{mg} / \mathrm{kg} /$ dia ou $60 \mathrm{mg}$ (72 mg no caso de Concerta $\left.{ }^{\circledR}\right) .{ }^{10} \mathrm{Na}$ maioria dos casos em que a PHDA afecta essencialmente o rendimento escolar, preconiza-se tratamento descontínuo, com interrupção aos fins-de-semana, feriados e férias (dias em que não há exigência acrescida da escola). No entanto, em situações de maior gravidade, com comportamentos muito perturbadores em casa, pode recorrer-se a um esquema contínuo.

Estão disponíveis várias formulações, de eficácia semelhante e tempo de acção variável, e a sua escolha depende das actividades de cada criança (Quadro VI). ${ }^{10}$

O fármaco escolhido deve ter uma duração de acção que possa abranger todo o período escolar. As de curta duração de acção serão administradas em horário correspondente a determinadas actividades da criança e requerem duas ou três tomas diárias. São a esco- 


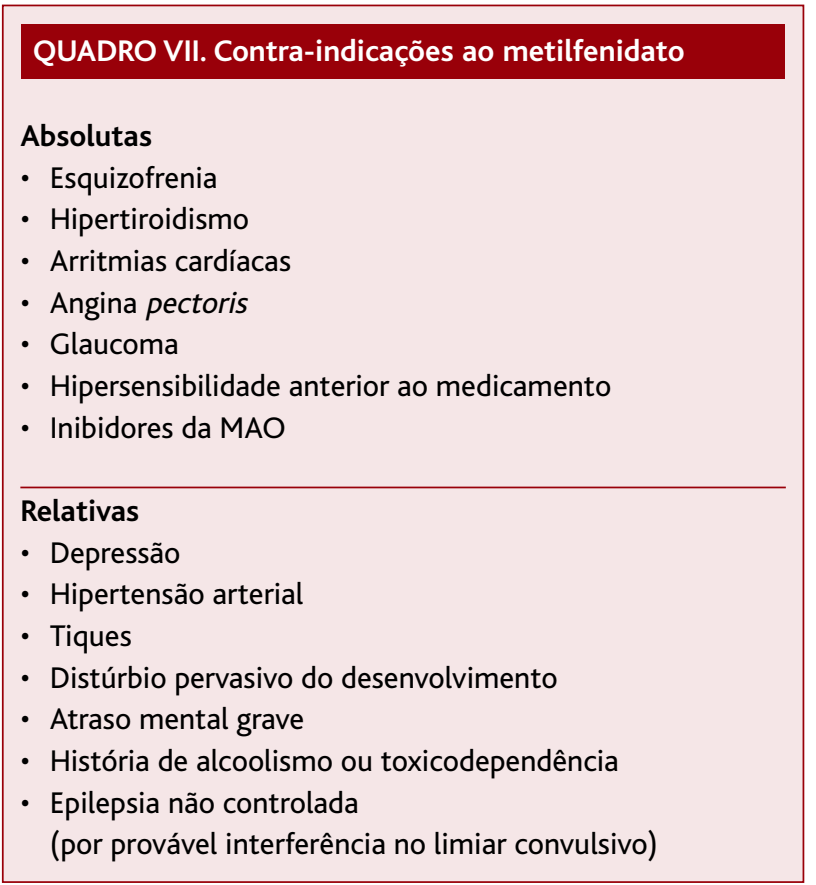

Abreviaturas: MAO: Monoaminooxidase

lha preferencial em crianças com peso inferior a $16 \mathrm{~kg}$ (nas quais as outras formulações não permitem doses suficientemente baixas), ou em crianças mais velhas, até obter uma dose eficaz. As formulações de acção intermédia ou prolongada evitam as tomas durante o horário escolar e são preferenciais pelo menos nas crianças mais velhas. Implicam uma única toma diária e controlam os sintomas por um intervalo de tempo superior, o que pode melhorar a adesão ao tratamento. ${ }^{10,47,48}$

Preconiza-se iniciar o tratamento com doses mais baixas e ir fazendo ajustes, a cada uma a três semanas, até que seja atingida a dose máxima, haja remissão dos sintomas, ou surjam efeitos secundários. ${ }^{4,6,10}$ A grande maioria dos indivíduos com PHDA, sem comorbilidades, responde à medicação estimulante. Se após um período suficientemente longo de tratamento, em doses adequadas, não há resposta, deve reconsiderar-se o diagnóstico. É particularmente importante considerar patologias associadas, que podem ser a causa primária do défice de atenção ou de controlo de impulsos. ${ }^{10}$ No caso de coexistirem perturbações afectivas ou distúrbio de ansiedade, é aconselhável a referenciação à Pedopsiquiatria. ${ }^{10}$ Apesar de serem situações raras, devem ter-se em consideração as contra-indicações ao tratamento com Metilfenidato (Quadro VII).

Recomenda-se monitorização do tratamento um mês após o seu início, para avaliar a eficácia, efeitos secundários e, eventualmente, ajustar a dose. ${ }^{10}$ Depois de estabelecido o tratamento eficaz, o acompanhamento deve fazer-se pelo menos a cada seis meses. Em todas as consultas deve verificar-se a adesão ao tratamento, a presença de efeitos secundários (tiques, depressão, irritabilidade, entre outros) e pesquisar sintomas e comportamentos que possam sugerir comorbilidades. Preconiza-se uma reavaliação anual da necessidade de manter o tratamento, em função da informação de pais e professores, no início de cada ano escolar, após um período inicial sem medicação. ${ }^{4,6}$

No caso de falha terapêutica, comorbilidades ou efeitos secundários graves, pode recorrer-se a fármacos alternativos, de segunda linha, que não estão aprovados pela Food and Drug Administration (FDA), para o tratamento de PHDA. É o caso dos antidepressivos tricíclicos, risperidona, clonidina, guafancina e bupropion..$^{10} \mathrm{~A}$ utilização da atomoxetina, no tratamento da PHDA, foi aprovada pela FDA em 2002. Trata-se de um fármaco simpaticomimético de acção central, inibidor da recaptação da noradrenalina, não estimulante, comprovadamente eficaz e seguro. Recentemente disponível no mercado nacional, pode ser usado em alternativa ao Metilfenidato, quando coexistem ansiedade ou tiques e tem uma duração de acção de cerca de 24 horas.

\section{EVOLUÇÃO E PROGNÓSTICO}

Diversos factores influenciam a evolução e o prognóstico nem sempre é favorável. A PHDA é um problema crónico, capaz de afectar significativamente o desempenho académico, social, familiar, emocional e laboral, ao longo de toda a vida. ${ }^{2}$ Em estudos longitudinais de follow-up, constatou-se que em 60 a $85 \%$ dos casos, o diagnóstico persiste durante a adolescência, ou seja, na maioria dos casos não cura com o início da puberdade..$^{10,11,27}$ Neste grupo etário, os sintomas de desatenção e impulsividade assumem maior importância em relação à hiperactividade; mostram dificuldades significativas de concentração, impulsividade e problemas na interacção social, que poderão causar dificuldades na progressão académica ou no trabalho, nas relações interpessoais, baixa auto-estima, ansiedade e labilidade emocional. Estima-se que cerca de $30 \%$ serão adul- 
tos sem problemas; terão pior evolução, 10 a 15\% dos casos, com problemas anti-sociais e psiquiátricos importantes, como o abuso de álcool e drogas, criminalidade, depressões graves e risco de suicídio.

Estão identificados diversos factores que podem condicionar um prognóstico mais adverso:6,12 o momento do diagnóstico e início de intervenção são o factor mais importante; a presença de comorbilidades, particularmente características comportamentais de agressividade e perturbação da conduta e de oposição, são desfavoráveis na evolução do distúrbio. Também o défice cognitivo, o insucesso escolar, a presença de psicopatologia familiar (incluindo antecedentes familiares de PHDA), e o baixo nível socio-económico e cultural, são factores que pioram o prognóstico.

Estima-se que, entre 30 a $60 \%$ dos indivíduos afectados possam manter sintomas significativos, enquanto adultos. ${ }^{49} \mathrm{~A}$ prevalência neste grupo etário será de $4,4 \%$, variando esse valor na literatura disponível em função dos instrumentos e critérios de diagnóstico utilizados. ${ }^{10,50}$ Adultos não tratados terão taxas mais elevadas de perturbação da conduta, dificuldades laborais, depressão, comportamentos anti-sociais e criminais, acidentes, problemas conjugais e abuso de álcool ou drogas. ${ }^{10,49,50} \mathrm{~A}$ intervenção oportuna, visando melhorar o rendimento escolar, a aquisição de competências emocionais, sociais e mecanismos compensatórios pode influenciar o prognóstico de forma positiva.

\section{CONCLUSÕES}

A PHDA é o distúrbio neuro-comportamental mais frequente na criança. O diagnóstico é essencialmente clínico e baseado em critérios comportamentais, que estão sujeitos a subjectividade na avaliação.

Pediatras e outros profissionais dos cuidados de saúde primários têm um papel fundamental no reconhecimento precoce, avaliação e orientação desta condição. Essa atitude pode modificar definitivamente o percurso académico e psicossocial das crianças afectadas.

\section{REFERÊNCIAS BIBLIOGRÁFICAS}

1. Boavida J. Hiperactividade ou "má educação"? Saúde Infantil 2006; 28 (2): 3-5.

2. Rappley MD. Clinical practice: Attention deficit-hyperactivity disorder. N Engl J Med 2005 Jan 13; 352 (2): 165-73.

3. American Psychiatric Association. Diagnostic and statistical manual of mental disorders. 4th ed. Text Revision (DSM-IV-TR). Washington, DC:
American Psychiatric Association; 2000.

4. Taylor E, Döpfner M, Sergeant J, Asherson P, Banaschewski T, Buitelaar J, et al. European clinical guidelines for hyperkinetic disorder - first upgrade. Eur Child Adolesc Psychiatry 2004; 13 Suppl 1: 7-30.

5. American Academy of Pediatrics, Committee on Quality Improvement and Subcommittee on Attention-Deficit/Hyperactivity Disorder. Clinical practice guideline: diagnosis and evaluation of the child with attention-deficit/hyperactivity disorder. Pediatrics 2000 May; 105 (5): 1158-70.

6. Boavida JE, Porfírio H, Nogueira S, Borges L. A criança hiperactiva. Saúde Infantil 1998, 20 (3): 21-30.

7. Kutcher S, Aman M, Brooks SJ, Buitelaar J, van Daalen E, Fegert J, et al. International consensus statement on Attention-Deficit/Hyperactivity Disorder (ADHD) and disruptive behavior disorders (DBDs): clinical implications and treatment practice suggestions. Eur Neuropsychopharmacol 2004 Jan; 14 (1): 11-28.

8. Staller J, Faraone SV. Attention-Deficit/Hyperactivity Disorder in girls: epidemiology and management. CNS Drugs 2006; 20 (2): 107-123.

9. Biederman J, Mick E, Faraone SV, Braaten E, Doyle A, Spencer T, et al. Influence of gender on attention deficit hyperactivity disorder in children referred to a psychiatric clinic. Am J Psychiatry 2002 Jan; 159 (1): 36-42.

10. Pliszka S; American Academy of Child and Adolescent Psychiatry Work Group on Quality Issues. Practice parameter for the assessment and treatment of children and adolescents with attention-deficit/hyperactivity disorder. J Am Acad Child Adolesc Psychiatry 2007 Jul; 46 (7): 894$-921$.

11. Wolraich ML, Wibbelsman CJ, Brown TE, Evans SW, Gotlieb EM, Knight JR, et al.Attention-deficit/hyperactivity disorder among adolescents: a review of the diagnosis, treatment, and clinical implications. Pediatrics 2005 Jun; 115 (6): 1734-46.

12. Fernandes A. Perturbação de Hiperactividade com Défice de Atenção. Acta Paediatr Port 2001; 32 (2): 91-8

13. Faraone SV, Doyle AE. The nature and heritability of attention-deficit/hyperactivity disorder. Child Adolesc Psychiatr Clin N Am 2001 Apr; 10 (2): 299-316.

14. Banerjee TD, Middleton F, Faraone SV. Environmental risk factors for attention-deficit hyperactivity disorder. Acta Paediatr 2007 Sep; 96 (9): 1269-74.

15. Faraone SV, Khan SA. Candidate gene studies of attention-deficit/hyperactivity disorder. J Clin Psychiatry 2006; 67 Suppl 8: 13-20.

16. Thapar A, Langley K, Owen MJ, O'Donovan MC.Advances in genetic findings on attention deficit hyperactivity disorder. Psychol Med 2007 Dec; 37 (12): 1681-92.

17. Wohl M, Purper-Ouakil D, Mouren MC, Adès J, Gorwood P. Meta-analyse des genes candidats dans le trouble déficit attentionel avec hyperactivité (TDAH). Encephale 2005 Jul-Aôut; 31 (4 Pt 1): 437-47.

18. Thapar A, O'Donovan M, Owen MJ. The genetics of attention deficit hyperactivity disorder. Hum Mol Genet 2005 Oct 15; 14 (2): R275$-82$.

19. Langley K, Holmans PA, van den Bree MB, Thapar A et al. Effects of low birth weight, maternal smoking in pregnancy and social class on the phenotypic manifestation of Attention Deficit Hyperactivity Disorder and associated antisocial behaviour: investigation in a clinical sample. 
BMC Psychiatry 2007 Jun 20; 7: 26.

20. Linnet KM, Dalsgaard S, Obel C, Wisborg K, Henriksen TB, Rodriguez A, et al. Maternal lifestyle factors in pregnancy risk of attention deficit hyperactivity disorder and associated behaviors: review of the current evidence. Am J Psychiatry 2003 Jun; 160 (6): 1028-40.

21. Linnet KM, Wisborg K, Obel C, Secher NJ, Thomsen PH, Agerbo E, et al. Smoking during pregnancy and the risk for hyperkinetic disorder in offspring. Pediatrics 2005 Aug; 116 (2): 462-7.

22. Mick E, Biederman J, Faraone SV, Sayer J, Kleinman S. Case-control study of attention-deficit hyperactivity disorder and maternal smoking, alcohol use, and drug use during pregnancy. J Am Acad Child Adolesc Psychiatry 2002 Apr; 41 (4): 378-85.

23. Milberger S, Biederman J, Faraone SV, Jones J. Further evidence of an association between maternal smoking during pregnancy and attention deficit hyperactivity disorder: findings from a high-risk sample of siblings. J Clin Child Psychol 1998 Oct; 27 (3): 352-8.

24. Button TM, Thapar A, McGuffin P. Relationship between antisocial behaviour, attention-deficit hyperactivity disorder and maternal prenatal smoking. Br J Psychiatry 2005 Aug; 187: 155-60.

25. Knopik VS, Heath AC, Jacob T, Slutske WS, Bucholz KK, Madden PA, et al. Maternal alcohol use disorder and offspring ADHD: disentangling genetic and environmental effects using a children-of-twins design. Psychol Med 2006 Oct; 36 (10): 1461-71.

26. Pascual-Castroviejo I. Síndrome de deficit de atención con hiperactividad. Guía práctica diagnóstica y terapeútica. Barcelona: César Viguera Editorial; 1999.

27. Steer CR. Managing attention deficit/hyperactivity disorder: unmet needs and future directions: unmet need and future directions. Arch Dis Child 2005; 90 Suppl 1: i19-25.

28. Conners CK. Conners Rating Scales-Revised. Toronto: Multi-Health Systems; 1997.

29. Achenbach TM, Edelbrock C: Manual for the child behavior checklist and revised child behavior profile. Burlington, VT: University of Vermont, Department of Psychiatry; 1983.

30. Kadesjö B, Gillberg C. The comorbidity of ADHD in the general population of Swedish school-age children. J Child Psychol Psychiatry 2001 May; 42 (4): 487-92.

31. Gillberg C, Gillberg IC, Rasmussen P, Kadesjö B, Söderström H, Råstam $\mathrm{M}$, et al. Co-existing disorders in ADHD - implications for diagnosis and intervention. Eur Child Adolesc Psychiatry 2004; 13 Suppl 1: 180$-92$.

32. Jensen PS, Hinshaw SP, Swanson JM, Greenhill LL, Conners CK, Arnold LE, et al. Findings from the NIMH Multimodal Treatment Study of ADHD (MTA): implications and applications for primary care providers. J Dev Behav Pediatr 2001 Feb; 22 (1): 60-73.

33. Jensen PS, Garcia JA, Glied S, Crowe M, Foster M, Schlander M, et al. Cost-effectiveness of ADHD treatments: findings from the multimodal treatment study of children with ADHD. Am J Psychiatry 2005 Sep; 162 (9): 1628-36

34. Barkley RA. Psychosocial treatments for attention-deficit/hyperactivity disorder in children. J Clin Psychiatry 2002; 63 Suppl 12: 36-43.

35. Gonçalves FJ. Desordem por Défice de Atenção com Hiperactividade: a escola e a DDAH. Disponível em: http://ddah.planetaclix.pt/ddah_escola.htm [acedido em 22/12/2007].
36. Pascual-Castroviejo I. Síndrome de déficit de atención con hiperactividad y capacidad para el deporte. Rev Neurol 2004 Jun 1-15; 38 (11): 1001-5.

37. Greenhill L, Kollins S, Abikoff H, McCracken J, Riddle M, Swanson J, et al. Efficacy and safety of immediate-release methylphenidate treatment for preschoolers with ADHD. J Am Acad Child Adolesc Psychiatry 2006 Nov; 45 (11): 1284-93.

38. Connor DF. Preschool attention deficit hyperactivity disorder: a review of prevalence, diagnosis, neurobiology, and stimulant treatment. J Dev Behav Pediatr 2002 Feb; 23 (1): S1-9.

39. Firestone P, Musten LM, Pisterman S, Mercer J, Bennett S.. Short-term side effects of stimulant medication are increased in preschool children with attention-deficit/hyperactivity disorder: a double-blind placebo-controlled study. J Child Adolesc Psychopharmacol 1998; 8 (1): 13-25.

40. Mannuzza S, Klein RG, Moulton JL 3rd. Does stimulant treatment place children at risk for adult substance abuse? A controlled, prospective follow-up study. J Child Adolesc Psychopharmacol 2003 Fall; 13 (3): 273-82.

41. Faraone SV, Wilens T. Does stimulant treatment lead to substance use disorders? J Clin Psychiatry 2003; 64 Suppl 11: 9-13.

42. Wilens TE, Faraone SV, Biederman J, Gunawardene S. Does stimulant therapy of attention-deficit/hyperactivity disorder beget later substance abuse? A meta-analytic review of the literature. Pediatrics 2003; 111 (1): 179-85.

43. Biederman J, Wilens T, Mick E, Spencer T, Faraone SV. Pharmacotherapy of attention-deficit/hyperactivity disorder reduces risk for substance use disorder. Pediatrics 1999 Aug; 104 (2):e20. Disponível em: http://pediatrics.aappublications.org/cgi/content/full/104/2/e20 [acedido em 20/12/2007].

44. Boavida J, Cirino D, Pedro A. O uso de psicoestimulantes numa Consulta de Desenvolvimento. Workshop "Perturbação de Défice de Atenção e Hiperactividade". Pico, Açores, 17 de Maio de 2005.

45. Swanson JM, Elliott GR, Greenhill LL, Wigal T, Arnold LE, Vitiello B, et al. Effects of stimulant medication on growth rates across 3 years in the MTA follow-up. J Am Acad Child Adolesc Psychiatry 2007 Aug; 46 (8): 1015-27.

46. Spencer TJ, Faraone SV, Biederman J, Lerner M, Cooper KM, Zimmerman B; Concerta Study Group. Does prolonged therapy with a longacting stimulant suppress growth in children with ADHD? J Am Acad Child Adolesc Psychiatry 2006 May; 45 (5): 527-37.

47. Wilens T, Pelham W, Stein M, Conners CK, Abikoff H, Atkins M, et al. ADHD treatment with once-daily OROS methylphenidate: interim 12month results from a long-term open-label study. J Am Acad Child Adolesc Psychiatry 2003 Apr; 42 (4): 424-33.

48. Pelham WE, Gnagy EM, Burrows-Maclean L, Williams A, Fabiano GA, Morrisey SM, et al. Once-a-day Concerta methylphenidate versus three times-daily methylphenidate in laboratory and natural settings. Pediatrics 2001 Jun; 107 (6): e105. Disponível em: http://pediatrics. aappublications.org/cgi/content/full/107/6/e105 [acedido em 22/12/2007].

49. Harpin VA. The effect of ADHD on the life of an individual, their family, and community from preschool to adult life. Arch Dis Child 2005 Feb; 90 Suppl 1:2-7. 
50. Kessler RC, Adler L, Barkley R, Biederman J, Conners CK, Demler O, et al. The prevalence and correlates of adult ADHD in the United States: results from the National Comorbidity Survey Replication. Am J Psychiatry 2006 Apr; 163 (4): 716-23.

51. American Academy of Child and Adolescent Psychiatry. Guidelines pocketcard managing: attention deficit/hyperactivity disorder, version 1.1. Baltimore: International Guidelines Center; 2003.

\author{
ENDEREÇO PARA CORRESPONDÊNCIA \\ José Boavida \\ Centro de Desenvolvimento da Criança \\ Hospital Pediátrico de Coimbra \\ Avenida Bissaya Barreto \\ 3000-075 Coimbra
}

Recebido em 10/03/2008

Aceite para publicação em 17/7/2008

\section{ABSTRACT}

Introduction: Attention-Deficit Hyperactivity Disorder (ADHD) is the most frequent neurobehavioral disorder in school age children. The ways in which this disorder manifests itself vary and the symptoms must be given attention to whenever they impair the child's school work and its emotional and social balance.

Goal: To carry out an ADHD literature review, highlighting aspects that refer to epidemiology, etiopathogeny, clinical manifestations, diagnosis, evaluation, comorbilities and differential diagnosis, therapeutic intervention and prognosis.

Methods: The Medline and Pubmed databases were researched for articles and review articles published until December 2007. 45 articles were included in this review. A documental research was also conducted in reference works.

Conclusions: ADHD is a chronic behavioral disorder that can significantly affect one's lifelong academic, familiar, emotional, social and professional performances. A careful evaluation allows for the diagnosis, which is mainly of a clinical nature and based on behavioral criteria. Seldom is there an indication for complementary diagnosis exams. Other associated disorders are a risk factor towards a less positive evolution, and potential comorbilities must be considered. The therapeutic intervention must be individualized and the approach must be multidisciplinary, including, for the majority of cases, behavioral modifications and a resort to psychoactive substances. Various factors have an influence on the evolution, and the prognosis is not always favorable.

This literature review intends to contribute to the clearing up of the inclusiveness of a prevailing pathology that is often under-diagnosed and underestimated.

Keywords: Attention-Deficit Hyperactivity Disorder; Diagnosis; Non-pharmacological intervention; Methylphenidate; Prognosis. 